\title{
Modeling Breakage Kinetics in Various Dry Comminution Systems ${ }^{\dagger}$
}

\author{
D. W. Fuerstenau \\ Department of Materials Science and \\ Engineering, University of California* \\ and P. C. Kapur \\ Department of Metallurgical Engineering, \\ Indian Institute of Technology**
}

A. De

$A B B$. Inc

\begin{abstract}
In modeling comminution systems, breakage rate (selection) functions are generally influenced more by the comminution machine than are breakage distribution functions, which are controlled by material properties. Linear grinding kinetics can be expressed either in terms of grinding time or specific energy consumption. Nonlinearities are caused by energy transfer mechanisms in the comminution machine whereby coarser particles might be ground preferentially or are protected by fines, by energy dissipation through interparticle friction in compressed bed comminution, and sometimes from heterogeneities produced in the feed particles. This paper discusses modifications of breakage rate functions in the grinding model for a number of situations and compares simulated and experimental results.
\end{abstract}

\section{INTRODUCTION}

The optimal design and control of comminution circuits require a mathematical model capable of depicting the size reduction behavior of every size fraction for grinding conditions of technological importance. This is particularly important for modeling closed-circuit comminution systems in which oversize material from a classifier or screen is recycled back to the comminution device. Comminution kinetics did not really have any practical application until a mathematical model of batch grinding was introduced - a model that incorporated both disappearance and production kinetics into one mathematical construct. A rigorous mathematical approach to comminution was published in 1954 by Bass [1] but the catalyst that led to worldwide utilization of this so-called population balance model (or batch grinding model) to the analysis of comminution in tumbling mills was perhaps the 1962 paper presented by Gardner and Austin [2] at the First European Comminution Symposium.

\footnotetext{
* Berkeley, CA 94720-1760, USA

* Kanpur, India

† Accepted: September 9, 2003
}

The batch-grinding model entails the formulation of a mathematical model which is phenomenological in nature in that it lumps together the entire spectrum of stress-application events which prevail in the system under a given set of operating conditions. The appropriately defined average of these individual events is considered to characterize the over-all breakage properties of the device and material. A single parameter is assumed to represent the resistance of particles of that size (or size fraction) to fracture, given the average grinding environment which exists in the mill. The isolation of such a parameter and a related set of quantities which constitute the breakage product size distribution for the average event in this size fraction allows the formulation of physically meaningful descriptive equations capable of yielding detailed information for simulation. The continuous-time, sizediscretized solution of the batch grinding equation by Reid [3] provides a valuable practical simplification for data treatment since size distributions of comminuted products are usually determined in terms of a series of finite size intervals by sieving.

In dry batch ball milling, grinding kinetics follow a linear model. Linear breakage kinetics are said to prevail in a mill when neither the probability of breakage 




of a pertige (as measured by the breakage rate function) nor the distribution of fragments resulting from the primary breakage of that particle (as measured by the breakage distribution function) is influenced by the size consist in the mill. However, the rate of particle breakage may deviate from linearity due to changes in the nature of the comminution events or from changes in the heterogeneity of the particles being ground. For example, in some cases conditions may exist where the larger particles are ground preferentially or in other cases the larger particles may become protected after time. Under wet grinding conditions, at lower pulp densities suspension of the fine particles in the slurry may lead to an increase in the probability of coarser particles being ground, or at high pulp densities the slurry may become so viscous that grinding is retarded unless a grinding aid is added. In confined particle bed grinding, the product particles can be weakened through the generation of flaws and microcracks and consequently exhibit widely distributed strength behavior, which leads to nonlinearities in the regrinding of such particles. This paper discusses approaches taken to modify the model to describe that behavior.

\section{THE LINEAR BATCH GRINDING KINETIC MODEL}

Consider the size range of a particulate assembly, characterized by a maximum size, $\mathrm{x}_{1}$, and a minimum size $\mathrm{x}_{\mathrm{n}+1}$ to be subdivided into $\mathrm{n}$ intervals (with $\mathrm{n}$ sieves). The $\mathrm{i}$ th size fraction is the interval bounded by $x_{i}$ above and $x_{i+1}$ below and denote the mass fraction of material in this size interval at time $t$ by $m_{i}(t)$. If $r$ is the geometric sieve ratio (which is generally $\sqrt{2}$ for a series of sieves such as the Tyler sieve series), then $\mathrm{x}_{1}=\mathrm{rx}_{\mathrm{i}+1}$.

The Reid solution to the size-discretized integrodifferential equation of grinding kinetics yields a mass balance for the material in the $i$ th size interval in a batch ball mill at any time t:

$$
\frac{d m_{i}(t)}{d t}=-k_{i}(t) m_{i}(t)+\sum_{j=1}^{i-1} k_{j} b_{i-j} m_{j}(t) ; i=1,2, \ldots .
$$

where the parameter $k_{i}$ is the breakage rate function (also called the selection function) for the solids in the i-th size interval which gives the fraction of material in size fraction $i$ that is broken out in time $t$ to $\mathrm{t}+\mathrm{dt}$, and $\mathrm{b}_{\mathrm{i}-\mathrm{j}}$ is the breakage distribution function and gives the fraction of progeny particles reporting to size $i$ when unit mass fraction of particles of size $j$ is broken.
If we consider the top size, first fraction only, then

$$
\frac{\mathrm{dm}_{1}(\mathrm{t})}{\mathrm{dt}}=-\mathrm{k}_{1} \mathrm{~m}_{1}(\mathrm{t})
$$

for first-order grinding kinetics where the breakage rate function is independent of time. Under these conditions, the behavior of the top fraction is predicted by the following relationship:

$$
\mathrm{m}_{1}(\mathrm{t})=\mathrm{m}_{1}(0) \exp \left(-\mathrm{k}_{1} \mathrm{t}\right)
$$

Several different methods have been used to determine breakage rate and breakage distribution functions experimentally. For example, individual interior size fractions have been replaced by radioactivelylabeled size fractions of the same feed material, a complicated technique that provides the greatest amount of information. In a simpler way, an insert fraction of a different material with some easily identifiable physical or chemical property has been used, such as using a quartz insert in a limestone bulk feed. Herbst and Fuerstenau [4] showed the mathematical and experimental basis for obtaining these parameters by batch grinding single-sized feed particles. The breakage distribution function is normalizable and can be considered invariant and will not be discussed further in this paper. However, there is a strong power law dependence of the breakage rate function on particle size, $\mathrm{x}$ :

$$
\mathrm{k}(\mathrm{x})=\mathrm{Ax}^{\alpha}
$$

where $\mathrm{A}$ is a constant depending on the material properties. In many of their simulations, Kelsall et al. [5] assumed $\alpha=1.0$. However, Herbst and Fuerstenau [4] showed that the value of $\alpha$ has the same value as the distribution modulus of the Gaudin-Schuhmann size distribution of the comminuted product. To obtain the necessary data, a series of batch grinds should be carried out in a test mill to quantify not only the breakage rate but also the breakage distribution functions.

Using a 254-mm diameter instrumented ball mill, a series of batch grinding experiments was carried out dry by Herbst and Fuerstenau [4,5] with $7 \times 9$ mesh $(2.8 \times 2.0 \mathrm{~mm})$ dolomite feed for various operating conditions: mill speeds $\mathrm{N}^{*}$, ball loads $\mathrm{M}_{\mathrm{b}}{ }^{*}$, and particle loads $\mathrm{M}_{\mathrm{p}}{ }^{*}$. Details of the instrumented torque mill and experimental procedures can be found in the these papers $[4,6]$. According to Eq. 3, a semilog plot of the fraction of feed material remaining in the top size vs. time in batch experiment will result in a straight line whose slope is proportional to the breakage rate function. Figure 1, which shows plots of batch data obtained for selected mill speeds, ball loads, and parti- 




Fig. 1 The influence of mill operating variables on the kinetics of disappearance of $7 \times 9$ mesh dolomite in dry batch ball milling.

cle loads (for two different batches of dolomite feed) illustrates the appropriateness of Eq. 2 for the range of operating variables tested. This figure also illustrates the strong dependence which feed disappearance kinetics have on mill operating conditions.

Herbst and Fuerstenau [4] experimentally ground a range of monosized dolomite feeds to obtain the dependence of breakage rate functions on particle size (and also found the cumulative breakage distribution function to be normalizable) and proved their predicted relation to zero order production kinetic phenomena. Figure $\mathbf{7}$ given later, illustrates the dependence of breakage rate functions on particle size for dry ball mill grinding.

Using the values of breakage rate functions for particles of different size fractions and the normalized breakage distribution functions, the Reid solution to the batch grinding equation was programmed for a digital computer and the grinding behavior was simulated. Figure 2 presents a comparison of the computed size distributions with the experimentally observed distributions. The simulation based on the linear batch grinding model indeed predicts the product size distribution over a wide range of grind times.

The very extensive experimental work carried out during the last four decades has proven the validity of the linear grinding model and the size-dependence of the breakge rate functions and the normalizability of

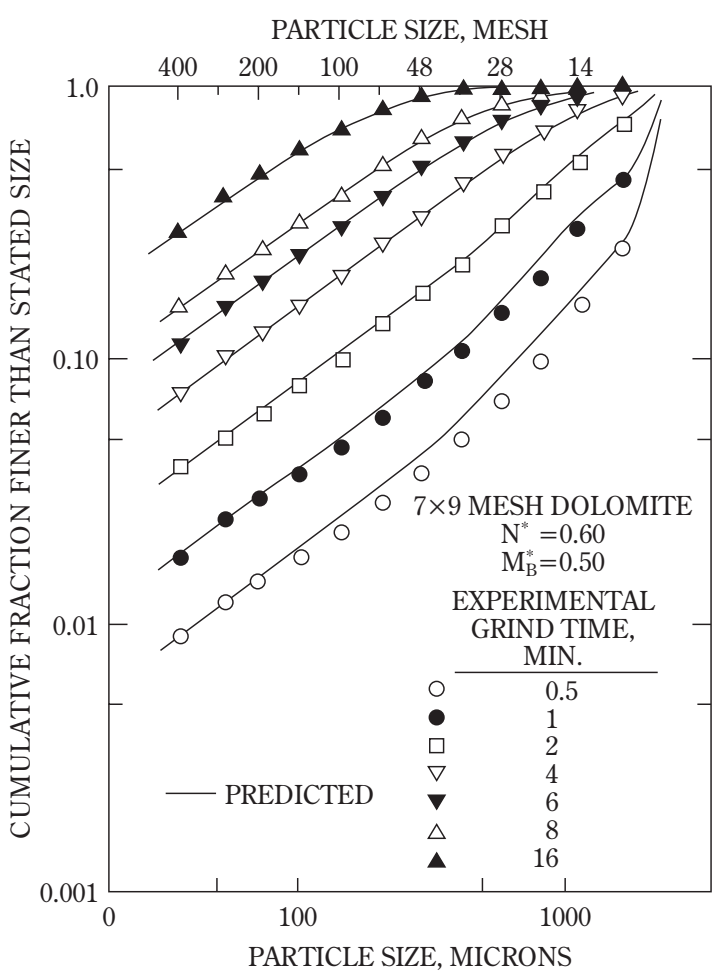

Fig. 2 Simulation of the comminution of $7 \times 9$ mesh dolomite feed using the Batch grinding equation and the experimentally determined values of the breakage rate and breakage distribution functions.

breakage distribution functions. With confidence it, therefore, is possible to back calculate these parameters for simulation purposes.

\section{THE NONLINEAR KINETIC MODEL FOR ROD MILL GRINDING}

Rod mill comminution represents a nonlinear grinding system, one in which the order is less than unity. In Eq. $1, k_{1}(t)$ represents the grinding rate function for monosized feed disappearance. There are two forms of $k_{1}(t)$ which have physical meaning. The first is

$$
\mathrm{k}_{1}(\mathrm{t}) \mathrm{m}_{1}(\mathrm{t})=\mathrm{k}_{1}(0) \mathrm{m}_{1}(0)
$$

which represents a "zero order" feed disappearance law where the feed grinding rate is constant for all time. This would occur if the grinding zones were saturated with respect to feed-size material and all comminution events are applied to feed-size particles. The second form of the breakage rate function is

$$
\mathrm{k}_{1}(\mathrm{t}) \mathrm{m}_{1}(\mathrm{t})=\mathrm{k}_{1}(0) \mathrm{m}_{1}(\mathrm{t})
$$


or $\mathrm{k}_{1}(\hat{2})=$ constant. This "first order" feed disappeararice voccurs when statistically independent comminution events are applied to an infinite particle population in a completely mixed environment, as exemplified by dry batch ball mill grinding. Non-integer order grinding does not have physical meaning, except possibly for systems that can be represented by an arbitrary linear combination of zero and first order kinetics. Such is the case for rod milling where bridging of coarse particles between the rods decreases the proportion of comminution events applied to the fines.

Grandy and Fuerstenau [7] proposed that for comminution systems which have apparent grinding orders less than one, the system can be modeled by a convex linear combination of zero and first order kinetics:

$$
\frac{\mathrm{dm}_{1}(\mathrm{t})}{\mathrm{dt}}=\phi_{1} \mathrm{k}_{1}(0) \mathrm{m}_{1}(\mathrm{t})+\left(1-\phi_{1}\right) \mathrm{k}_{1}(0) \mathrm{m}_{1}(\mathrm{t})
$$

where $\phi_{1}$ and $\left(1-\phi_{1}\right)$ give the respective fraction of first and zero order kinetics assumed, For rod mill grinding with kinetics that follow the foregoing relationship, the behavior of the top size material is predicted by Eq. 8:

$$
\mathrm{m}_{1}(\mathrm{t})=\frac{\mathrm{m}_{1}(0) \exp \left[-\phi_{1} \mathrm{k}_{1}(0) \mathrm{t}\right]}{\phi_{1}}+\frac{\left(1-\phi_{1}\right) \mathrm{m}_{1}(0)}{\phi_{1}}
$$

functions are environment-dependent. Since the grinding order is between zero and one, it is appropriate to fit Eq. 8 to the data. A semilog plot of $\left[\mathrm{m}_{1}(\mathrm{t})+\right.$ $\left.\mathrm{m}_{1}(0)\left(1-\phi_{1}\right) / \phi_{1}\right]$ vs. time should give a straight line with slope equal to $-\phi_{1} \mathrm{k}_{1}(0)$. For the foregoing rod mill grinding data, it was found by trial and error that a value of 0.91 for $\phi_{1}$ gave the best straight line for feed loads.

To carry out computer simulations of these rod mill grinding tests, the mathematical representation of the environment dependence is given by

$$
\mathrm{k}_{\mathrm{i}}\left(\mathrm{t}_{2}\right)=\mathrm{k}_{\mathrm{i}}\left(\mathrm{t}_{2}\right) \phi_{\mathrm{i}}+\left(1-\phi_{\mathrm{i}}\right)\left(\frac{\mathrm{m}_{1}\left(\mathrm{t}_{1}\right)}{\mathrm{m}_{1}\left(\mathrm{t}_{2}\right)}\right) \text { where } \mathrm{t}_{1}<\mathrm{t}_{2}
$$

Using the technique of Herbst and Fuerstenau [4] to estimate the size dependence of all the breakage rate parameters and the fraction of first-order grinding given in Figure 4, the dry batch rod milling of the $7 \times 9$ mesh dolomite was accurately simulated. Since The simulated plots and experimental date fit exactly [7], those results are not presented here.

In a detailed investigation of the wet grinding of dolomite in the batch ball mill, Yang [8] found that plots of feed size breakage kinetics had the same shape as those shown in Figure $\mathbf{3}$ for rod mill grinding. This means that under the conditions of Yang's experiments (60\% solids), the fine product particles tended to be suspended in the slurry inside the mill



Fig. 3 First order feed disappearance plot for rod mill grinding at several different feed loads in the batch mill.

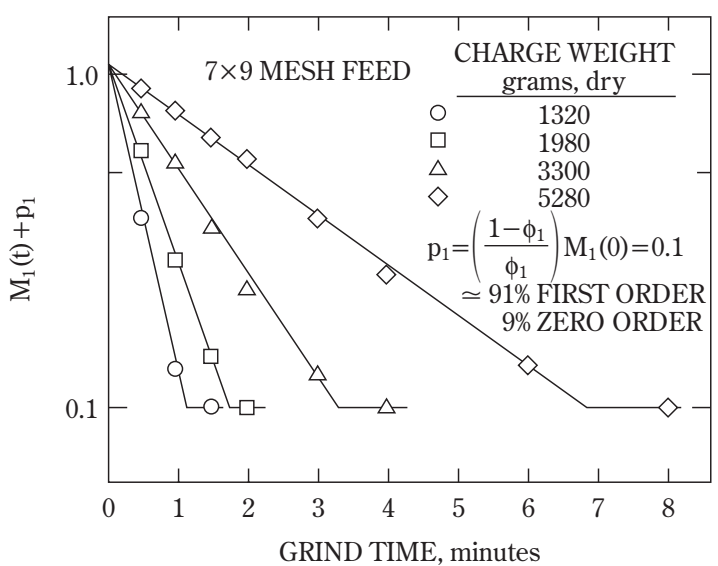

Fig. 4 Linear combination of first order and zero feed disappearance kinetics in dry rod milling. 
wath the result that there was some preferential grinding of the coarser particles under those conditions. WOn the other hand, Klimpel [8] found that the disappearance kinetics plots for the fine wet grinding of coal at $57 \%$ solids density were first order but at $73 \%$ solids density became strongly concave as grinding progressed. Under these conditions the slurry inside the mill becomes increasingly viscous. As grinding progressed the rate of disappearance of feed size coal was significantly retarded. But by adding a polymeric grinding aid, which reduced the slurry viscosity markedly, Klimpel [8] was able to return the grinding kinetics to first order.

\section{LINEAR GRINDING KINETICS EXPRESSED IN TERMS OF SPECIFIC ENERGY}

In conducting their batch grinding experiments with dolomite feed under a wide range of operating conditions, Herbst and Fuerstenau [6] also accurately measured the specific energy consumed by their mill. An anaysis of the grinding kinetics in the dry ball mill revealed that the size-discretized breakage rate functions are proportional to the specific energy input to the mill and that the breakage distribution functions can be taken as invariant. Taking the experimental results used to prepare the plots given in Figure 1 for a range of mill speeds, mass of solids in the mill, and the mass of grinding balls in the mill, the results are replotted and presented in Figure 5 using spe-

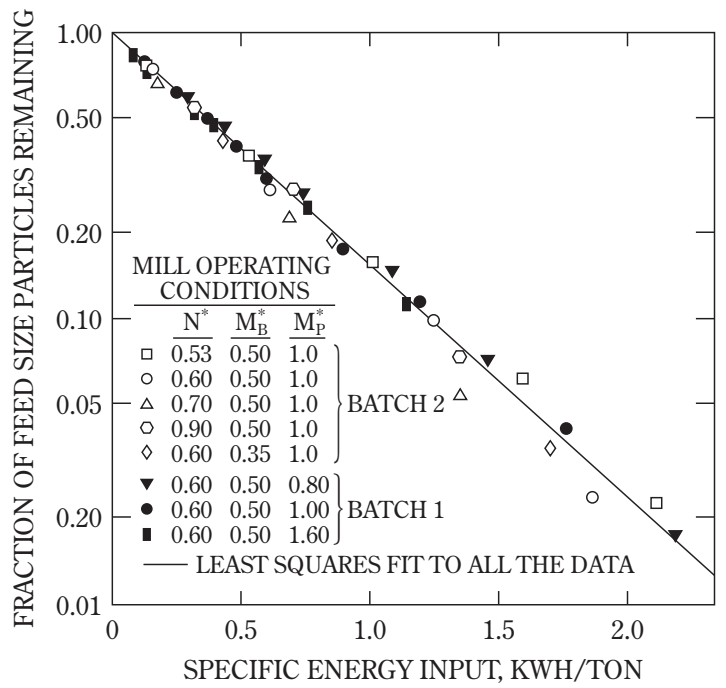

Fig. 5 Feed disappearance kinetics normalized with respent to specific energy in $\mathrm{kWh}$ per ton of feed material. cific energy as the independent variable instead of time.

Based on that extensive experimentation, Herbst and Fuerstenau [6] showed that over a fairly wide range of conditions the feed size breakage rate function can be approximated by

$$
\mathrm{k}_{1}=\mathrm{k}_{1}^{\mathrm{E}}\left(\frac{\mathrm{P}}{\mathrm{M}_{\mathrm{p}}}\right)
$$

where $P$ is the power input to the mill, $M_{p}$ is the mass of feed material in the mill, and $\mathrm{k}_{1}^{\mathrm{E}}$ is a constant. From Eq. 9, we can write the batch response for the first interval:

$$
\mathrm{m}_{1}(\mathrm{t})=\mathrm{m}_{1}(0) \exp \left[-\mathrm{k}_{1}^{\mathrm{E}}\left(\frac{\mathrm{P}}{\mathrm{M}_{\mathrm{p}}}\right) \mathrm{t}\right]
$$

Since the product of specific power and time is equal to the net specfic energy input to the mill, $\overline{\mathrm{E}}, \mathrm{Eq} .10$ can be expressed alternatively as

$$
\mathrm{m}_{1}(\overline{\mathrm{E}})=\mathrm{m}_{1}(0) \exp \left(-\mathrm{k}_{1}^{\mathrm{E}} \overline{\mathrm{E}}\right)
$$

The preceding analysis leads to expressing the batch grinding equation in terms of specific energy expended rather than in terms of grinding time as follows

$$
\frac{d m_{i}(\bar{E})}{d E}=-k_{i}^{E} m_{i}(\bar{E})+\sum_{j=1}^{i-1} k_{i}^{E} b_{i-j} m_{j}(\bar{E})
$$

The fact that breakage kinetics can be accurately analyzed in terms of specific energy instead of time, has become very useful, with regard to mill scale-up and the analysis of other types of comminution systems, such as the roll mill.

Malghan and Fuerstenau [9] conducted a detailed study of the scale-up of ball mills using the population balance grinding model normalized through specific power input to the mills. In their investigation, they constructed three instrumented and scaled batch ball mills : 5-inch $(12.7 \mathrm{~cm})$ diameter, 10-inch $(25.4 \mathrm{~cm})$ diameter, and 20 -inch $(50.8 \mathrm{~cm})$ diameter. They dry ground $8 \times 10$ mesh $(2.4 \times 1.7 \mathrm{~mm})$ limestone. They found that the feed size breakage rate functions for all three different mill speeds, ball loads and feed loads in each mill fell on a single line when the feed size disappearance was plotted as a function of expended energy. Likewise, the breakage distribution function for all of the grinds were self-similar, completely independent of mill size and mill operating conditions. To illustrate the utility of the specific energy reduced breakage rate function concept, Figure 6 presents the experimental size distributions obtained from grinding the $8 \times 10$ mesh limestone in the 20 -inch mill 
PARTICLE SIZE, MESH

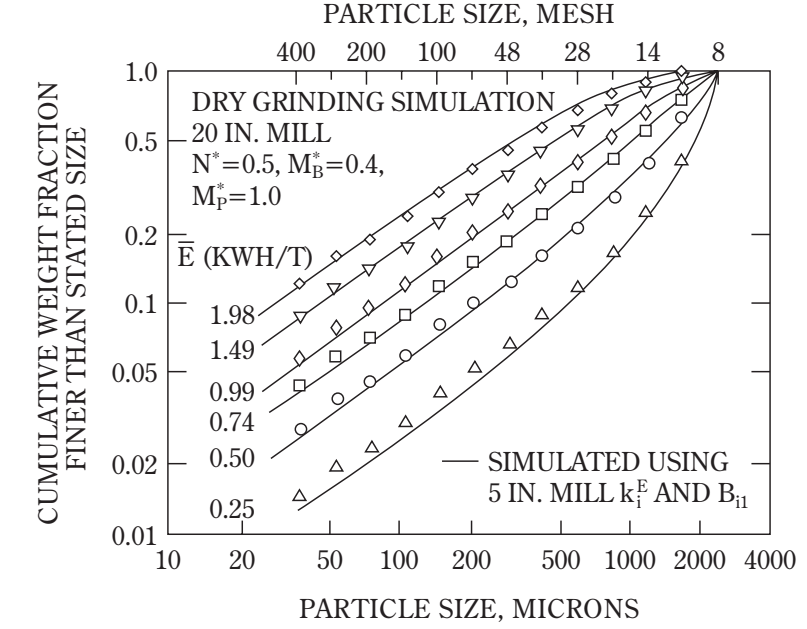

Fig. 6 Comparison of experimentally determined size distributions and those Predicted for grinding $8 \times 10$ mesh limestone in a 20 -inch $(50.8 \mathrm{~cm})$ diameter mill, using breakage rate and breakage distribution functions obtained from grinding the same material in the 5 -inch $(12.7-\mathrm{cm})$ mill.

and the simulation of grinding using the breakage parameters determined from grinds carried out in the 5-inch mill.

Malghan and Fuerstenau [9] also showed that if the breakage rate function were expressed in time rather than specific energy, for the range of mill speeds, ball loads, and feed loads, it would be proportional to $\mathrm{D}^{0.56}$ and proportional to $\left(\mathrm{D}-\mathrm{d}_{\mathrm{b}}\right)$ where $\mathrm{D}$ is the mill diameter and $d_{b}$ is the ball diameter. The reduced breakage rate function simplifies analysis and design considerably since there would be no necessity for achieving kinematic and loading similarity. Scaling with time would require that the mills be compared at the same fraction of critical rotational speed.

Expressing grinding kinetics in terms of specific energy instead of grinding time also clarifies the complex behavior observed in wet grinding at high solids content [10].

\section{MODELING NONLINEAR HIGH-PRESSURE ROLL MILL COMMINUTION}

After single-particle breakage, the next most efficient method of comminution is particle-bed comminution [11,12]. In this mode, comminution occurs primarily by very high localized interparticle stresses generated within the particle bed. No separate carrier is employed for the transport of energy to the solids, unlike in tumbling mills. Particle bed comminution is carried out continuously in a device comprised of two counter-rotating rolls. As the feed particles pass through the roll gap, the particle bed is compressed and the coarser particles undergo an isostatic-like compression by the fine particles in which the coarser ones are embedded. Energy is lost in the high-pressure roll mill due to friction between the particles as they pass through the roll gap and due to the ineffectiveness of the isostatic loading phenomenon.

There really is no explicit running grinding time in the high-pressure roll mill, only a fixed time of passage of solids through the grinding zone of the rolls in a more or less plug flow manner. Therefore, in order to simulate roll-mill grinding, it is necessary to formulate the population balance model in terms of energy input to the mill. In addition, as the particle bed or column passes down through the rolls, it is compacted and densified and compacted more and more with an increasing rate of energy dissipation due to interparticle friction and incipient visco-plastic flow. Consequently, the energy component that actually goes into stressing the particle to fracture is progressively reduced. Kapur et al. [13] proposed that the increase in retardation of the breakage rate with energy input can be incorporated into the population balance model by defining a rescaled energy:

$$
\mathrm{E}^{\prime}=\frac{1}{1-\mathrm{y}} \mathrm{E}^{1-\mathrm{y}} \text { where } 0 \leq \mathrm{y}>1
$$

For high-pressure roll mill grinding, the population balance equations for grinding kinetics can be formulated in terms on cumulative energy input, taking into account energy dissipation in accordance with Eq. 13, to yield the following relation:

$$
\frac{d m_{i}(E)}{d E}=-\frac{k_{1}^{o}}{E^{y}} m_{i}(E)+\sum_{j=1}^{i-1} \frac{k_{j}^{o}}{E^{y}} b_{i-j} m_{j}(E)
$$

Fuerstenau et al. [13] determined the product size distributions for grinding quartz, limestone and dolomite at various energy expenditures in a laboratory high-pressure roll mill (roll diameter of $200 \mathrm{~mm}$ ) and from the results estimated the breakage rate and breakage distribution parameters. For each of these materials, the breakage distribution functions have essentially the same shape as those found for other comminution systems, such as the ball mill and rod mill. However, the breakage rate functions all remain quite high at all particle sizes, unlike in a ball mill where the specific rate constants drop sharply with particle size, especially in the medium and fine particle size range (the slope of a log-log plot of k-vs-size being the distribution modulus). Figure 7 compares 


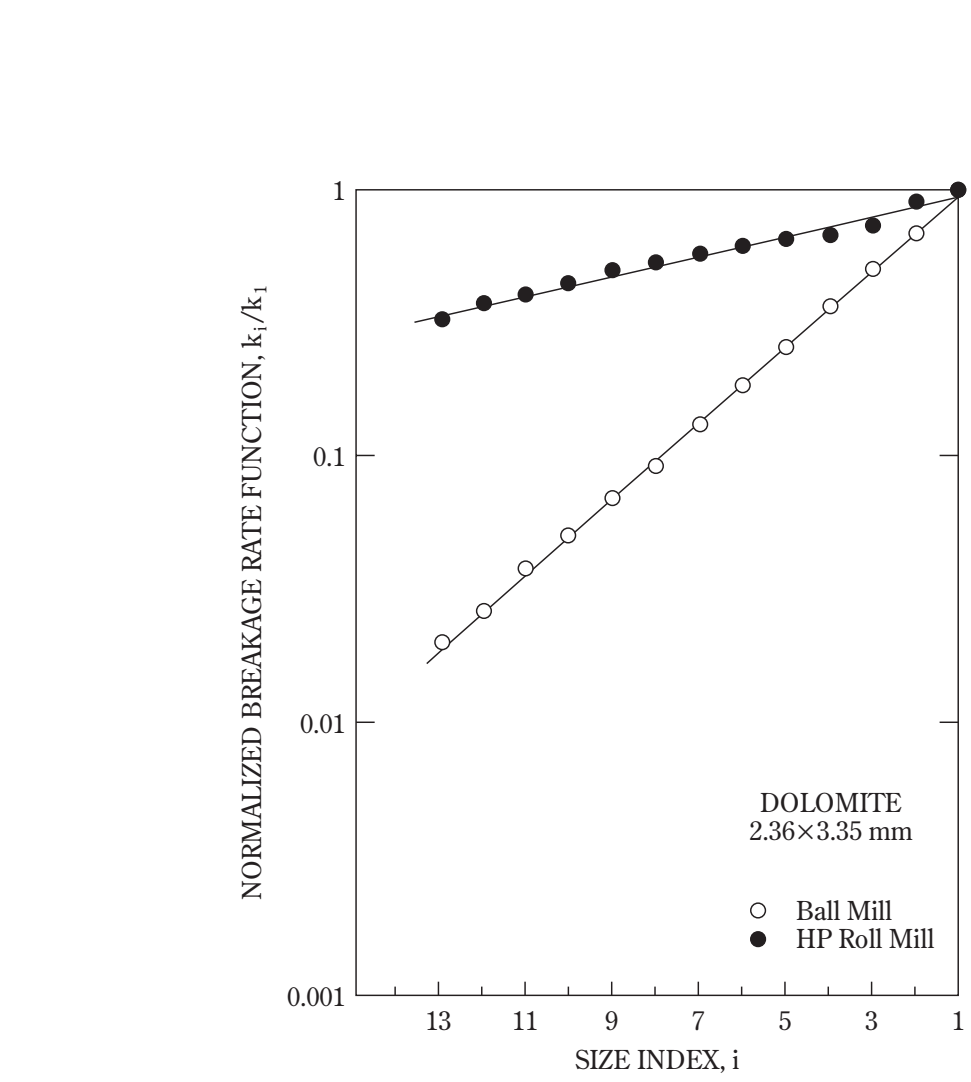

Fig. 7 The effect of particle size on the estimated breakage rate functions for dolomite being ground in the high-presssure roll mill and a ball mill (size index $1=8 \times 10$ mesh here).

the effect of particle size on the breakage rate function for grinding dolomite in the high-pressure roll mill with grinding the material in a dry ball mill. As a consequence of this, the pressurized roll mill can perform size reduction much more efficient energy-wise than the ball mill. This probably explains the greater energy efficiency of the high-pressure roll mill at lower reduction ratios. The reason that the breakage rate functions for the high pressure roll mill appear to have only a small particle size effect must result from the energy transfer mechanism in the roll mill, namely that the high compression stresses are transferred from one particle to another as they pass through the roll gap, in contrast to the probabilistic nature of stress transfer in a ball mill. This apparently is the crucial difference between the two kinds of grinding mills. As a consequence, the pressurized roll mill can perform size reduction tasks much more efficiently energy-wise than the ball mill (at lower reduction ratios).

With the breakage rate parameters estimated from the high-pressure roll milling experiments, the size distributions of dolomite, limestone, and quartz were simulated with the population-balance grinding equation that had been suitably modified to account for energy dissipation in the roll gap (Eq. 15). Figure 8 shows the simulation of grinding quartz in the highpressure roll mill at three different energy levels [13]. The simulations of the size distributions of the roll mill products are in good agreement with the experimentally determined size distributions.

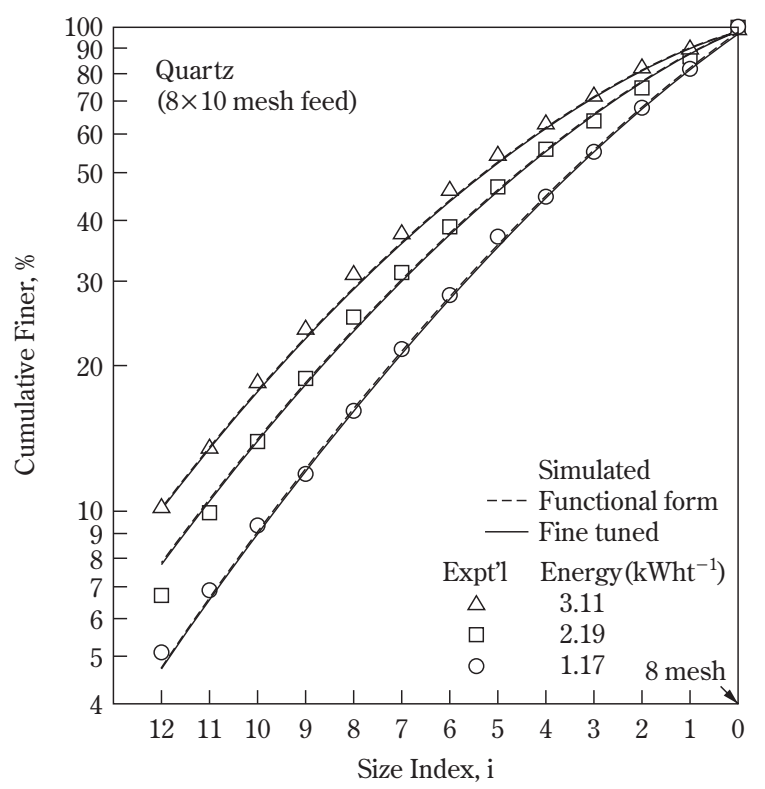

Fig. 8 Experimental and simulated size distributions of quartz ground in a high-pressure roll mill at different energy levels.

\section{MODELING THE KINETICS OF GRINDING DAMAGED PARTICLES}

Significant energy savings can be gained by using a two-stage grinding system which utilizes the efficiency of the high-pressure roll mill at low reduction ratios and the higher efficiency of ball mills at high reduction ratios [14]. As discussed in the foregoing section, particle breakage in the roll mill occurs through interparticle loading of the feed as it passes through the roll gap. Because the particles are not loaded by impact, as in ball milling, but by direct transmission of stresses from one particle to another, high-pressure roll mill grinding results in progeny particles that are broken, cracked, damaged or otherwise weakened. Consequently, the particles are distributed in strength which implies that the rate at which these particles will be ground in a ball mill will also be distributed. As already discussed, the linear population balance model used routinely for the simu- 
lationobof ball mill grinding of ordinary feeds assumes assingle-valued rate parameter for particles of a given size fraction.

In order to successfully use the population balance approach to model the ball mill grinding of material that has first been ground in the high-pressure roll, we need to account for the pronounced heterogeneity in strength (or ease of grinding) of the high-pressure roll mill product particles [15]. We have noted earlier that the parameter A in Eq. 4 is a function of the material properties. In the simulation of batch ball milling of primary particles, A could be assumed to be constant, without affecting the quality of simulation. We can account for the heterogeneity in the strength of high-pressure roll-milled particles by letting A be variable. It is reasonable to say that $A$ is a measure of the ease with which the particles could be broken, that is, a measure of the grindability. The larger the value of A, the easier it would be to break the particle. While primary particles are expected to be relatively uniform in strength, the particles in the high-pressure roll mill product are damaged and weakened to different extents, that is, that are distributed in $\mathrm{A}$. We assume, however, that the distribution is independent of the particle size. In our analysis, we consider that the distribution in the grinding rate parameter, $\mathrm{k}$, of the high-pressure roll mill product can be described by a modified gamma function:

$$
\mathrm{m}(\mathrm{A})=\frac{\lambda^{\beta}\left(\mathrm{A}-\mathrm{A}_{0}\right)^{\beta-1}}{\Gamma(\beta)} \exp \left[-\lambda\left(\mathrm{A}-\mathrm{A}_{0}\right)\right] ; \mathrm{A}_{0} \leq \mathrm{A} \leq \infty
$$

where $A_{o}$ is the minimum grinding rate constant encountered in the ball mill. And $\beta$ and $\lambda$ are the shape and scale parameters of the distribution. By incorporating Eq. 16 into Eq. 12, and integrating, we obtain the expression for the mass fraction retained on size $\mathrm{x}$ after an energy expenditure of $\mathrm{E}_{\mathrm{b}}$ in ball milling the high-pressure roll mill product:

$$
R\left(x, E_{b}\right)=R(x, 0) \frac{\exp \left(-A_{o} x^{\alpha} E_{b}\right)}{\left(1+x^{\alpha} E_{b} / \lambda\right)^{\beta}}
$$

The shape and scale parameters are functions of the energy expenditure in the high-pressure roll milling stage.

These concepts were tested through a detailed study of the hybrid comminution of bituminous Pittsburgh No. 8 coal, that is for the open-circuit ball milling of coal that had first been ground in the highpressure roll mill. Figure 9 presents the experimental results of the mass fraction of ball mill product retained on a 200 -mesh sieve $(74 \mu \mathrm{m})$ as a function of the energy expended for ball mill grinding the pres- surized roll mill product, together with the computed results. In these experiments, the coal was first ground in the high-pressure roll mill (HPRM) at four different energy levels. Figure 10 presents the experimental and computed size distributions of the ground coal after it had been comminuted in the ball mill at different expenditures of energy in the ball mill step after first being roll-milled at an energy expenditure of $2 \mathrm{kWh} / \mathrm{t}$. The simulated results given in Figure $\mathbf{1 0}$ are in excellent agreement with experiment.

The distribution in the grindability of coal particles

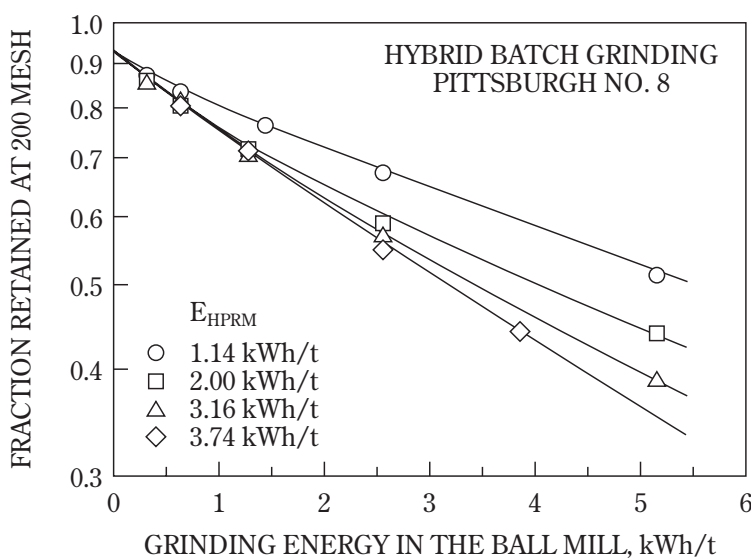

Fig. 9 For the hybrid grinding of Pittsburgh No. 8 coal, the fraction retained on a 200 -mesh sieve $(74 \mu \mathrm{m})$ sieve as a function of the energy expended in the ball mill on material that had been comminuted in the high-pressure roll mill at different HPRM energy levels: experimental data points and simulated curves.

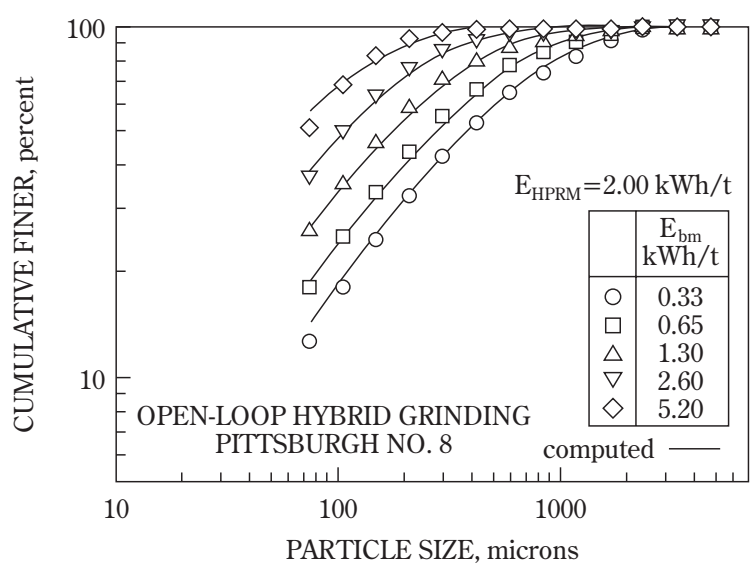

Fig. 10 Experimental and computed size distributions of Pittsburgh No. 8 coal produced by open-circuit hybrid ball mill grinding of material that had first been ground at an energy expenditure of $2 \mathrm{kWh} / \mathrm{t}$ in the HPRM. 
in the digh-pressure roll mill product was assessed by fitting the mathematical model to the experimental Wdata. Figure 11 was constructed to show plots of the calculated density functions $\mathrm{m}(\mathrm{k})$ representing the distribution of breakage rate functions of 200-mesh particles of Pittsburgh No. 8 coal produced at energy consumptions of 1.14, 2.0, 3.16 and $3.74 \mathrm{kWh} / \mathrm{t}$ in the HPRM. Although the coal is discharged from the HPRM in a briquetted form, the individual particles are easily separated by stirring in aqueous methanol to determine their size distribution, if desired [15]. The fact that the mean of the distributions shifts towards higher grinding rate values with increasing energy input to the high-pressure roll mill strongly suggest that these results and concepts are phenomenologically meaningful.

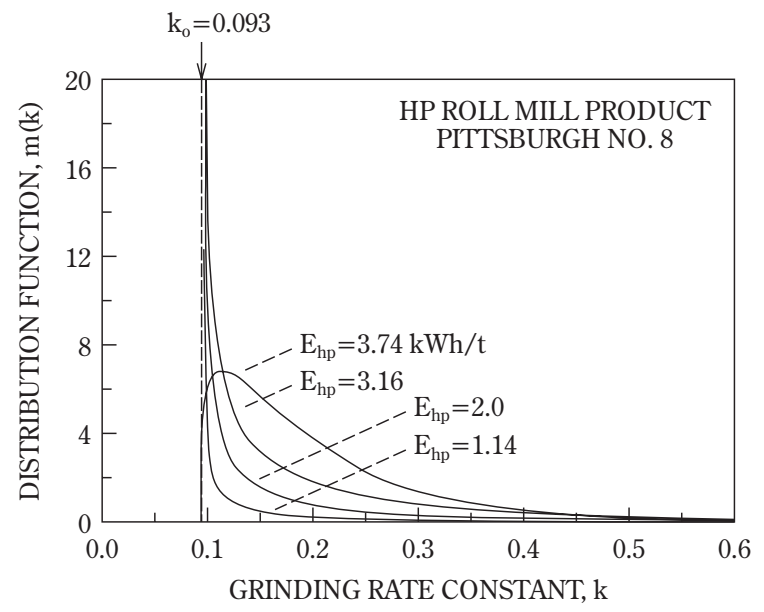

Fig. 11 Density functions for the distribution of the specific ball mill grinding rates of Pittsburgh No. 8 coal produced in the high-pressure roll mill at different energy inputs.

\section{OPTIMIZATION OF OPEN-CIRCUIT HYBRID GRINDING SYSTEMS}

The non-linearity of the kinetics of grinding primary particles in the high-pressure roll mill and the subsequent ball milling of the roll mill product present us with an interesting optimization problem. For open-circuit hybrid grinding, our goal would be to find the optimum energy expenditure in the highpressure roll mill that would result in maximum particle damage at minimum energy dissipation, and the energy expenditure range in the ball mill where the energy is primarily spent in breaking the damaged particles, that is the range where the ball mill grinding of damaged particles is essentially non-linear. Figure 12 presents the simulated production of minus 200-mesh product and the specific energy expenditure per ton of product, as a function of the energy input in the high-pressure roll mill and the ball mill per tonne of feed for the open-circuit grinding of Pittsburgh No. 8 coal.

The specific grinding energy contours are shown as solid lines, and the contours of percent fines produced are presented as dashed lines. The simulation results indicate that the percentage of minus 200mesh produced increases with the increase in grinding energy input in the ball mill for a given energy expenditure in the high-pressure roll mill. However, for a fixed energy input in the ball mill, the percentage of minus 200-mesh material produced goes through a maximum with increasing energy input in the highpressure roll mill. As the production of minus 200mesh particles increases, the high-pressure roll mill energy at which the maximum occurs shifts to higher energy values. The specific energy required to produce a unit weight of minus 200-mesh product, on the other hand, increases with the increase in energy input in both the ball mill and the high-pressure roll mill (except in the region defined by high-pressure roll mill energy between $1.75 \mathrm{kWh} / \mathrm{t}$ and $2.5 \mathrm{kWh} / \mathrm{t}$ and ball mill energy greater than $3.5 \mathrm{kWh} / \mathrm{t}$ ). At a given specific energy consumption, particularly at higher percentage of fines production, an optimum partition exists between the energy input in the high-

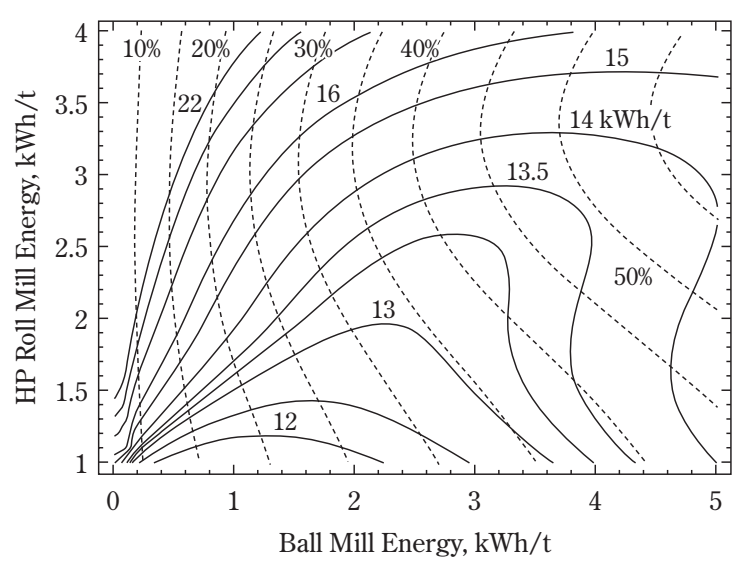

Fig. 12 Relationship between specific grinding energy (solid lines) and the percentage of minus 200 mesh $(74 \mu \mathrm{m})$ fines produced (dashed lines) at different energy inputs in the high-pressure roll mill and the ball mill in open-circuit hybrid grinding of Pittsburgh No. 8 bituminous coal. 
pressare rof mill and the ball mill in order to achieve anavimum percentage of minus 200-mesh product. For example, at a specific energy consumption of $13.25 \mathrm{kWh} / \mathrm{t}$ of minus 200-mesh product, the energy input should be $2.5 \mathrm{kWh} / \mathrm{t}$ of feed in the high-pressure roll mill and $3.2 \mathrm{kWh} / \mathrm{t}$ in the ball mill in order to produce a comminuted product with 43 percent of minus 200-mesh fines.

Because of the visco-plastic nature of coal, it is possible that the potential energy saving resulting from the fracturing and weakening of the particles as they are stressed in the HPRM could be more than offset by the increased briquetting at the high compressive stresses at higher energy expenditures in the pressurized roll mill step. Thus, a maximum benefit might be expected from the hybrid grinding of coal at an optimal energy expenditure in the high-pressure roll mill. In Figure 13, the percentage of energy saved through the hybrid grinding mode relative to the energy expended in ball mill grinding alone for the production of a fixed amount of fines is plotted against the energy expended in the HPRM step. These plots clearly show that not only is there an optimum for the energy input to the high-pressure roll mill but also the energy saving is negated if the energy expenditure in the high-pressure roll mill is higher than a threshold value, which would depend on the nature of the coal and the percentage of fines produced. There is a similar optimum for the hybrid grinding of minerals than can deform plastically, such as calcite and dolomite [14].

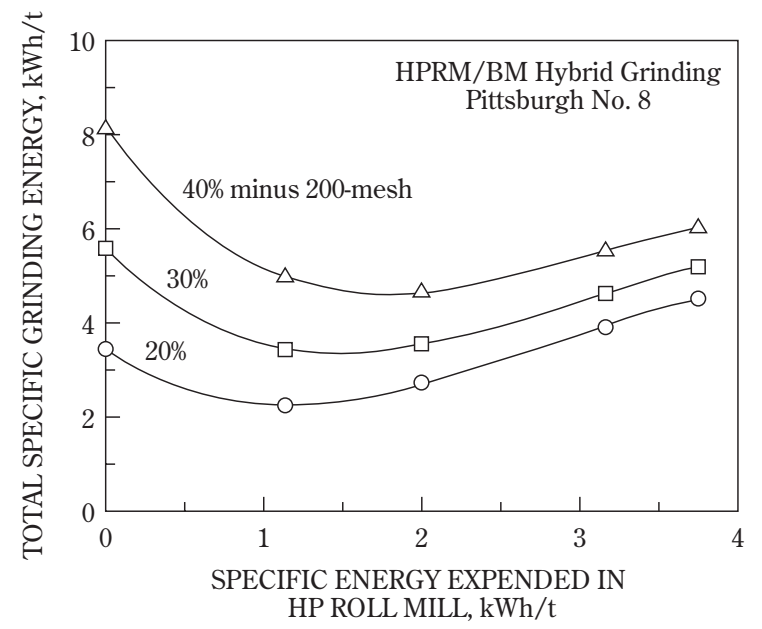

Fig. 13 Relationship between the total specific comminution energy and the energy expenditure in the high-pressure roll mill for the production of minus 200-mesh fines in the hybrid grinding of Pittsburgh No. 8 coal.

\section{SUMMARY}

Industrial comminution processes are inherently nonlinear. The extent of nonlinearity is governed by the mill characteristics, comminution environment, and the material properties. However, over a limited range of time or energy input, the processes could be treated as linear and modeled accordingly. For instance, in the initial stages of dry batch ball milling, grinding kinetics follow a linear model. Linear breakage kinetics prevail in the mill as neither the probability of breakage of a particle (as measured by the breakage rate function) nor the distribution of fragments resulting from the primary breakage of that particle (as measured by the breakage distribution function) is significantly influenced by the size consist in the mill. In the rod mill, on the other hand, where the larger particles are ground preferentially, the initial grinding behavior is significantly nonlinear. The nonlinearity can be modeled in such cases by suitably modifying the breakage probability function.

The change in the grinding environment in the media mills, over time, also leads to nonlinear comminution kinetics in these mills. This is primarily because of reduced energy utilization at larger grinding times due to particle shielding under dry grinding conditions, or increased slurry viscosity in wet grinding. Such nonlinearities can be easily resolved by recasting the grinding model equations in terms of energy input, instead of the grinding time. Expressing grinding kinetics in terms of energy instead of time also leads to simplifications in grinding mill scale up.

For confined particle bed grinding, as in highpressure roll milling, due to the energy dissipation through interparticle friction and isostatic stresses at higher confining pressures, can only be modeled as a nonlinear process. A modified population balance model, that explicitly handles the retardation in energy utilization, has been presented. The modified model results in fairly accurate simulation of highpressure roll mill grinding.

High pressure roll milling results in product particles that may become can be weakened though the generation of flaws and microcracks and consequently exhibit widely distributed strength behavior. This leads to nonlinearities in the regrinding of such particles in media mills. We have incorporated this distribution in particle strength into the batch ball mill grinding model and successfully simulated the open-circuit hybrid grinding of coal, where coal particles are first ground in the high-pressure roll mill and then in the ball mill. Experimental as well as simula- 
tion results indicate that optimum specific energy per tan of product of desired fineness could be achieved Why operating each of the mills in appropriate regimes. The optimal operating conditions and the energy partitioning would be dictated by the material properties and fineness of product.

\section{REFERENCES}

[1] L. Bass (1954), Zeits. Angew. Math. Phys., 5, 283-292.

[2] R. P. Gardner and L. G. Austin (1962), Symposium Zerkleinern, 1st European Symposium on Comminution, ed. H. Rumpf and D. Behrens, Verlag Chemie, Weinheim, 217-248.

[3] K. J. Reid (1965), Chemical Engineering Science, 20, 953-963.

[4] J. A. Herbst and D. W. Fuerstenau (1968), Trans. SME/AIME, 241, 528-549.

[5] D. F. Kelsall, K. J. Reid, and C. J. Stewart (1969-1970), Powder Tech., 3, 170-179.

[6] J. A. Herbst and D. W. Fuerstenau (1973), Trans.
SME/AIME, 254, 343-347.

[7] G. A. Grandy and D. W. Fuerstenau (1970), Trans. SME/AIME, 247, 348-354.

[8] R. R. Klimpel (1982), Powder Technology, 32, 267-277.

[9] S. Malghan and D. W. Fuerstenau (1976), in Zerkleinern, Dechema-Monographien, Verlag Chemie, GMBH, 613-630.

[10] D. W. Fuerstenau, K. S. Venkataraman and B. V. Velamakanni (1985), International Journal of Mineral Processing, 15, 251-267.

[11] K Schoenert (1988), International Journal of Mineral Processing, 22, 401-412.

[12] D. W. Fuerstenau and P. C. Kapur (1995) Powder Technology, 82, 51-57.

[13] D. W. Fuerstenau, A. Shukla and P. C. Kapur (1991), International Journal of Mineral Processing, 32, 59-79.

[14] A. De (1995), Modeling and Optimization of Fine Grinding of Minerals in High-Pressure Roll Mill/Ball Mill Hybrid Comminution Circuits, Ph.D. Thesis, University of California, Berkeley.

[15] D. W. Fuerstenau and J. Vazquez-Favela (1997), Minerals and Metallurgical Processing, 13, 41-48. 


\section{w'Author's short biography}

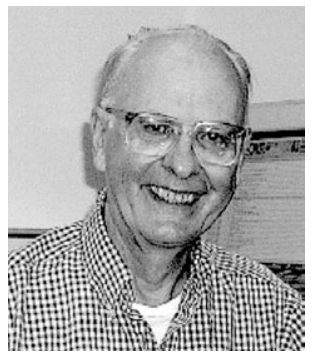

\section{W. Fuerstenau}

D. W. Fuerstenau received his Sc.D. degree in metallurgy (mineral engineering) from MIT in 1953. After a period in industry, he joined the faculty in the Department of Materials Science and Engineering of the University of California at Berkeley in 1959, where he continues as Professor in the Graduate School. He has been actively involved over the years in research on the processing of minerals and particulate materials, including extensive research on interfacial phenomena in these systems. Areas in which he has worked extensively include comminution, agglomeration, mixing, flotation and applied surface and colloid chemistry.

\section{P. C. Kapur}

P. C. Kapur received his M. S. degree in 1964 and his Ph.D. degree in materials science and engineering in 1968 from the University of California at Berkeley. After working at the Colorado School of Mines Research Foundation, he returned to India as Professor of Metallurgical Engineering at the Indian Institute of Technology at Kanpur. Since retiring from IIT Kanpur in 1995, he has been on the staff of Tata Research Development and Design Centre as Consulting Advisor. He is widely recognized for his extensive research on the processing of particulate materials, mainly agglomeration, comminution and size distributions, and particularly the mathematical modeling and computer simulation of processing operations.

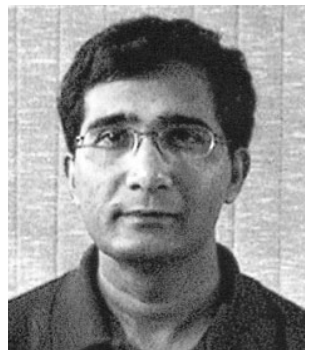

\section{A. De}

A. De received his B. Tech. degree in 1981 and M. Tech. degree in 1983 in metallurgical engineering from the Indian Institute of Technology at Kanpur. In 1994, he received his $\mathrm{Ph} . \mathrm{D}$. in materials science and engineering from the University of California at Berkeley. At Berkeley his major research efforts were directed towards the comminution of coal, including experimental investigations and mathematical modeling. He currently is Senior Software Engineer with ABB, Inc. 